\title{
Creando Buen Trato: una experiencia de prevención de la violencia de género desde el ámbito local ${ }^{1}$
}

"Creating good treatment" an experience to prevent gender violence from the local sphere"

\author{
Nuria Ramírez García \\ Unidad de Formación y \\ Sensibilización de la \\ Delegación de Igualdad y \\ Salud del Ayuntamiento de \\ Jerez \\ formación.igualdad@aytojerez.es
}

\section{Experiencias: campaña Buen Trato}

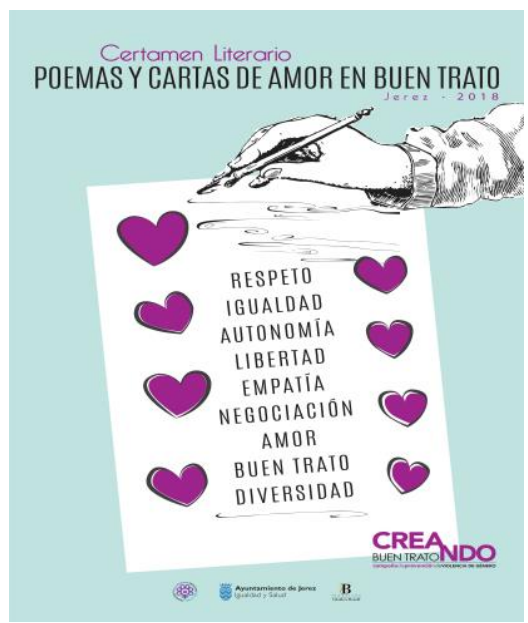

Con esta reseña pretendemos describir la campaña "Crea-ndo Buen Trato", experiencia en prevención de la violencia de género que hemos estamos llevando a cabo desde Unidad de formación y sensibilización de la Delegación de Igualdad y Salud del Ayuntamiento de Jerez de la Frontera a lo largo del curso escolar 2017-2018.

Hoy día resulta incuestionable la necesidad social de educar en valores de igualdad como estrategia para erradicar y prevenir la grave y compleja problemática de la violencia de género. Las instituciones públicas tienen el deber de materializar políticas, servicios y recursos que den respuesta a las necesidades sociales más apremiantes, como es la violencia de género, dicho deber queda recogido en la Ley Orgánica 1/2004 de 28 de diciembre, de Protección Integral contra la violencia de género y en la Ley 3/2017 de 22 de marzo para la Igualdad efectiva entre hombres y mujeres, y se reitera en el Pacto de Estado contra la violencia de género recién aprobado a nivel estatal. Las entidades locales, los ayuntamientos, por su cercanía a la ciudadanía pueden y deben cumplir un

${ }^{1}$ Recibido: 07/06/2018 Evaluado: 10/06/2018 Aceptado: 12/06/2018 
papel importante en el abordaje de la violencia de género, sobre todo en el ámbito de la prevención y sensibilización.

Desde este convencimiento la Delegación de Igualdad y Salud del Ayuntamiento de Jerez lleva más dos décadas desarrollando experiencias innovadoras ${ }^{2}$ en el ámbito de la prevención de la violencia de género y la educación en igualdad destinadas a la población joven de la ciudad, a los inicios de manera más puntual y menos sistematizada, a partir del año 2004 con un programación específica de carácter anual como apoyo al trabajo de educación en valores que se hacía en los centros educativos. En la actualidad este compromiso coeducativo y preventivo se ha materializado en la estructura organizativa de la Delegación Municipal, dentro del departamento de Violencia de Género como la Unidad de formación y sensibilización. La finalidad de la Unidad es promover estrategias y experiencias de sensibilización, formación en igualdad y prevención de la violencia de género destinadas a diferentes sectores poblacionales de manera coordinada con los diferentes agentes sociales de la Ciudad.

En este contexto de trabajo en coordinación y cooperación con agentes sociales, surge la campaña "Crea-ndo Buen Trato. Prevención de violencia de género" de la que a continuación vamos a describir y destacar los aspectos claves.

La campaña de ámbito local se inicia en noviembre de 2017 con motivo de la conmemoración del Día Internacional contra la violencia de género, su programación tiene carácter anual.

Como objetivos generales nos planteamos incidir en el ámbito de la prevención de la violencia de género en población adolescente y joven, concienciar sobre la responsabilidad de todas las personas como miembros de la sociedad tanto en el ámbito social como personal en el cambio de valores hacia una sociedad libre de violencias machistas y visibilizar modelos de relación afectiva, construidos sobre la base del respeto a derechos humanos, donde primen valores de igualdad, libertad, autonomía, corresponsabilidad, diversidad, etc.

Elegimos el eslogan, "Crea-ndo Buen Trato. Prevención de la violencia de género" porque queríamos movilizar, promover en los/las destinatarios/as de las acciones una actitud activa y constructiva. Elegimos el verbo crear desde su significado de "acción o acto de materializar algo nuevo", junto a las palabras "buen trato" como términos que conceptualizan un modelo de relación amoroso sustentado en valores de respeto, igualdad, autonomía y libertad, modelo que protege frente a la violencia de género. Porque hemos querido poner el arte y la creatividad personal y social al servicio de la transformación de las relaciones afectivas, usando como herramientas expresiones artísticas variadas como son el teatro, la música, exposiciones, vídeos, fotografías, poesías, etc. para imaginar, describir, mostrar y poner en valor las relaciones afectivas en buen trato.

A lo largo del año se han puesto en marcha 16 acciones, unas en el ámbito de la sensibilización y otras educativas, destinadas en su mayoría a población joven, aunque

\footnotetext{
${ }^{2}$ En el año 2012 recibimos el Primer Premio del Concurso de Buenas prácticas locales contra la violencia de género concedido por el Ministerio de Sanidad, Servicios Sociales e Igualdad y la Federación Española de Municipios y Provincias (FEMP) con el proyecto "Te quiero con respeto. Construyendo relaciones afectivas positivas" de entre 90 propuestas que concursaron.
} 
también se contempló alguna acción para población general y otras específicas para profesionales. En total han participado unas 2.997 personas, 1.600 mujeres y 1.397 hombres. Este dato incluye solo las personas que directamente han asistido a las actividades programadas, pues no disponemos de herramientas cuantitativas para estimar el alcance de algunas de las acciones de sensibilización, como por ejemplo los spots en Onda Jerez.

La valoración general de la campaña ha sido muy positiva, tanto al interno de nuestra entidad, pues las actividades fueron evaluadas de manera satisfactoria por los/las participantes y se completó el aforo en la mayoría de las actividades programadas, como a nivel externo, por parte del Observatorio local de la violencia de género, el Consejo local de la mujer, la Red de Asociaciones contra la violencia de género y la comunidad educativa.

Entre las acciones de sensibilización destacamos los cuatro anuncios publicitarios realizados junto a Onda Jerez, protagonizados por dos chicos voluntarios alumnos del Instituto Santa Isabel de Hungría que reflejaron 4 situaciones machistas que suceden muy cotidianamente entre los jóvenes, dichos spots se han estado proyectando de manera continuada desde noviembre a marzo en la televisión local. Del merchandising con el eslogan de la Campaña se han editado y repartido 850 pegatinas y 1.200 pulseras. También se desatacan las representaciones teatrales "Las Flores del Rincón" y la obra de teatro foro "Naranjas a medias incomunicando", la Exposición la violencia de género a través del Cómic, el Espacio de conocimiento sobre violencia sexual en jóvenes, y la Jornada sobre violencia de género destinada a profesionales de la abogacía.

Entre las actividades educativas resaltamos los talleres "Relaciones de buen trato y prevención de la violencia de género", del que se han desarrollado 37 ediciones en 14 centros educativos de los siete distritos de la ciudad incluida zona rural, en los que han participado unos 1.100 alumnos/as de tercero y cuarto de secundaria y ciclos formativos. En el Encuentro inter centros "Creando Buen Trato" en el que los/las mismos/as jóvenes fueron agentes educativos de sus iguales y protagonistas del proceso de inicio a fin, queremos destacar que el mismo alumnado creó los productos audiovisuales sobre la temática del buen trato que presentaron en el espacio de "Encuentro" a alumnado de otros centros educativos. Y que estos vídeos han quedado como material pedagógico que puede ser usado en otras actividades. Esto mismo sucede en la actividad con la que queremos acabar esta reseña, el "Primer Certamen literario de poemas y cartas de amor en buen trato" destinado a alumnado escolarizado en centros de secundaria y bachillerato de la ciudad. Quisimos aprovechar la efeméride de San Valentín, en febrero para seguir cuestionando el modelo de amoroso romántico y seguir promocionando el modelo de buen trato fomentando en el alumnado la creación de poemas y cartas que reflejaran esta tipología de relación afectiva. El concurso tuvo gran acogida tanto en el profesorado como en el alumnado. Se concedieron los dos premios previstos en una emotiva Gala con música y literatura que fue coorganizada y protagonizada por alumnado y profesorado de los centros educativos de las alumnas premiadas, las componentes del Jurado que fallaron el Premio y personal de la Fundación José Manuel Caballero Bonald. 
Despedimos esta reseña evocando a la esperanza, a la transformación personal y amorosa que nos reflejan los dos poemas premiados en el "I Certamen literario de Poemas $y$ Cartas de Amor en Buen trato" 
Amor libre, amor bueno

Autora Marta I. Galán Jiménez,

alumna de $3^{\circ}$ E.S.O Colegio Laude Altillo School.

Amor.....

Amor tú, amor yo,

Amor libre y sincero,

Amor completo, amor entero

Esperanzas y sueños perseguidos,

comprensión, ayuda, crecimiento, veremos nuestros retos conseguidos, y alcanzaremos el cielo.

Camino recorrido juntos,

sin cadenas ni juramentos,

no asomarán entre nosotros los lamentos,

siendo dos y no uno.

Amor .....

Amor mi apoyo, amor mi logro.

Amor me quedo, amor lo siento.

Amor pleno y bueno,

Amor alegre, amor certero.

Siendo tú, siendo yo,

seremos ...

\section{Vértigo}

Autora Paula Villarreal González,

alumna de $1^{\circ}$ de Bachillerato de I.E.S. Seritium.

Estaba cansada de caminar sobre rascacielos.

Tenía los labios agrietados de tanto maquillarlos.

El pecho tapado,

el cabello bien peinado

y el corazón herido.

Revolución, pensó.

Se deshizo entonces de los tacones.

Borró el carmín de sus labios.

Se despeinó por primera vez

Y tiró a la basura todos,

pero que todos

los prejuicios.

Fue en ese momento cuando todo ocurrió.

Algunos dicen que se paró el tiempo

por un instante. 
Ella se quiso.

Y fíjate tú,

No le hizo falta nadie

para sentirse

completa 